\title{
Tourism publications as newly tradeable commodities: Academic performance, prestige, power, competition, constraints and consents
}

\author{
Ralf Buckley \\ International Chair in Ecotourism Research. Griffith University, 4222, Australia
}

The politically powerful Academic Ranking of World Universities now includes tourism ranks and scores, calculated as sums of university-total weighted square-root ratios of four publication parameters. The algorithm is capable of local pairwise computational solutions. Publications are more valuable to lower-ranked universities, despite similar production costs. This creates opportunities for arbitrage, and pressures for trade and purchase. Currently, universities purchase publications through indirect mechanisms such as fractional, emeritus, adjunct, and visiting appointments and affiliations. Countries and universities that adopted systems for direct purchase of articles between universities would gain a significant competitive advantage. The most immediate opportunity, with no legal or ethical barriers, is for pay-per-article contracts with newly-retired but still productive tourism professors.

Introduction

In the view of a pre-internet literary detective, "No piece of information is superior to any other" (Eco, 1988, p. 225). In university research, however, the reverse applies. Although Google ${ }^{\circledR}$ Scholar now allows us to find almost any information published anywhere, those pieces of information are not of equal value. Academic research information is arranged in very powerful vertical hierarchies. Its position depends on where it was published, and how often it was read, downloaded, and cited. The theoretical basis for this is the tree-of-knowledge concept, the idea that some types of knowledge are more fundamental and influential than others. A more accurate concept, perhaps, would be a forest of knowledge, since different disciplines have very different and often incommensurate hierarchies.

The practical basis is that since no individual person can keep track of all the knowledge that exists already, and all the new knowledge that is constantly being generated, we need systems to sort that knowledge, so that we can find the most relevant pieces. The entire system of academic journal publishing, with its disciplines and impact factors and specialist editors and reviewers, is a system for sorting information according to its perceived relative value at the time of publication. Although new multi-disciplinary open-access journals claim to publish any research that reflects sound methods, that is not what actually happens. They still use reviewers with expertise aligned to the topic of the article, and those reviewers judge value as well as soundness.

There is an indefinite amount of novel information that can be obtained reliably, but most of it is of little interest, e.g. because it is very localised. So, a hierarchy of knowledge is a necessity, for reliable knowledge to grow without being overwhelmed by trivia. Academic publishing also provides credentials, a check on reliability. This is also a necessity, to prevent reliable knowledge being buried 
in nonsense. Both of these functions are increasingly important, as information generation and dissemination continues to expand.

New and reliable ideas, insights and information are generated largely from formal research, disseminated to users as refereed research publications. Most research is conducted by universities, and this is seen as one of their principal social roles. In the same way that there are sortable value hierarchies of information and journals, there are corresponding hierarchies of universities, based on their contributions to high-value knowledge. Research performance of universities, in various fields of knowledge, is evaluated routinely through rating and ranking systems, which assign values to different publication parameters. These rankings are highly valued and contested by universities, because they are signals and signifiers of prestige or symbolic capital to their peers, staff, students, funders, and the public, and this prestige confers functional power.

Of the three most respected international rankings, only the Academic Ranking of World Universities (AWRU), also known as the Shanghai Rankings, focusses solely on refereed research publications. In addition, only the ARWU publishes a global ranking of research in tourism and the related fields of hospitality, sport and leisure. The first version of this ARWU tourism subject ranking was published in 2018. The effect of this ranking is that tourism research publications can be seen as commodities, coins or counters in earning a high score in a valuable source of prestige and power.

Here I examine the consequences of the ARWU tourism subject ranking, and the consequent commodification of tourism research publications, on the prestige competition between universities, and on the incentives and constraints that those universities impose on their tourism researchers. To achieve this, I deconstruct the ARWU data sources and algorithm so as to reproduce the published rankings. The structure of the algorithm, and especially its multi-parameter normalisation and aggregation steps, does not allow for a generalised algebraic optimisation solution. It does, however, allow for localised computational comparisons between institutions, and these are sufficient to compare potential competitive strategies for universities and for countries. A key aspect of these strategies is the direct or indirect trading of publications between institutions. Indirect trades already exist. Direct purchases do not, but I conclude that they are feasible, and would yield considerable competitive advantages.

Theoretical context: power, prestige, and rankings

Power \& prestige are linked

The principal theoretical context for this analysis is the link between socially visible prestige or symbolic capital, and functional power derived from differential accrual of resources. Most recent research on such links is based in the works of Foucault (1966) and Bourdieu (1979). The links between symbolic displays of power and prestige, and functional power, have been recognised since the earliest human civilisations, and are paralleled in other animal species, but these authors formalised those links into coherent theory. Their perspectives have been applied and analysed very extensively, in academia as elsewhere (Brosnan, 2016; Desrochers et al., 2018).

In a university context, the key consideration is that different degrees confer different social prestige, and this depends on country, institution, academic discipline, level, and grade. In some countries, prestige depends principally on institution; in others, principally on academic discipline (Kehm, 2014). The prestige of academic staff and alumni depends on the prestige of the university as 
well as individual achievements. The prestige of universities depends partly on history, and partly on achievements by academic staff and graduates. Ranking systems aim to summarise and signal prestige parameters for the convenience of stakeholders (Bougnol \& Dula, 2006; Kehm, 2014; Marginson, 2014; Shin et al., 2011).

Ranks themselves confer prestige, however, and if stakeholders rely more heavily on numerical ranks than the primary performance parameters, this generates positive feedback that further increases the importance of ranking systems in conferring prestige (Gioia \& Corley, 2002). In addition, since prestige attracts funding and other material resources, and creates preferences amongst potential staff and students, this generates a second positive feedback between prestige and functional power, as described by Foucault (1966) and Bourdieu (1979).

Universities, academic journals, and individual staff depend very heavily on this prestige. What sets universities apart from any other sources of information, knowledge and skill is that they alone have a legal right to confer degrees. Everything else in a university could be subcontracted. An educational institution could rent its land, buildings, vehicles, laboratories, and equipment; hire all its academic, technical, administrative and general staff on contracts; and buy all its teaching and assessment materials from publishers. With these, it could conduct and publish research, and train students. But without formal recognition as a university, it could not confer degrees. Unless these degrees are recognised as valuable and prestigious, therefore, the power of universities could collapse. Universities compete fiercely for funding and students, prestige is their primary weapon, and rankings confer prestige. Academic researchers, in tourism as in other disciplines, contribute to those rankings and are influenced by them, whether we approve of them or not (Espeland \& Sauder, 2007).

Prestige and power do not provide the only relevant theoretical perspective on university rankings. These rankings also influence the competitive advantage of nations (Porter, 2011) in the tertiary education export industry. National-scale ranking and rating programs are a key component of education policy in many countries (Rizvi \& Lingard, 2009; Bøyum, 2014; Johnes, 2018). They give students a tool to choose where they would prefer to study; but they also give universities funding, status, and power to decide which students can exercise their preferences (Himanen, Auranen, Puuska, \& Nieminen, 2009; Hicks, 2012). Rankings may also be considered from an information theory perspective (Peng, Yang, Cao, Yu, \& Xie, 2017). They involve information compression, where details are discarded in search of comprehensibility; and information sorting, where individual users rely on endorsement by others to identify information likely to be relevant and reliable.

Normative and instrumental perspectives on ranking systems

Numerous different ranking and rating systems exist (Franzoni, Scellato, \& Stephan, 2011). Ranking systems enumerate a list, whereas rating systems assign bands or tiers. Some systems combine both ranks and tiers. Some systems are national, others international. Some rank universities, whereas others rank countries, journals, or individual academics (Nkomo, 2009; Muller, 2017). Of the university ranking systems, some rank only entire institutions, whereas others rank individual subjects at each university. There are many different disciplinary and geographical components of scope and scale, multiple different public or proprietary databases of research inputs and outputs, and many different ways to select, weight, and aggregate individual parameters into overall numerical indices. Parameters considered differ between systems, with a primary division between 
those that consider only research, and those that also consider teaching, student outcomes, and related measures.

Ranking systems are strongly embedded in modern education systems (Ehrenberg, 2012; Kehm, 2014), but they have been criticised extensively (Gioia \& Corley, 2002; Giacalone, 2009; Gruber, 2014). Analyses and critiques may be classified into normative and instrumental approaches. The normative concern themselves with ends, the instrumental with means (Parisi, 2004; Hands, 2012; Bøyum, 2014). Normative considerations include, for example: the purposes of universities; the relative worth of different academic disciplines; and the value or otherwise of ranking exercises as a whole, of different ranking systems, and of the uses to which rankings may be put. Instrumental considerations include, for example: sources and reproducibility of data; comparative consequences of parameter selection, weighting, and calculation algorithms; statistical correlations between ranking measures and external para- meters; and outcomes and responses to rankings by various stakeholders.

From a normative perspective, different people hold different views on what universities should aim to do (De Fraja \& Valbonesi, 2012; Вøyum, 2014). Individuals may consider, for example, that the primary purpose of universities is to act as a repository of existing knowledge; or to create and disseminate new knowledge; or to identify practical applications of knowledge. They may believe that universities should train students to recognise, evaluate and create new knowledge; or gain professional employment qualifications; or appreciate the breadth and diversity of human civilisations. Some people think that a university education should be provided at taxpayer expense for every school leaver; others that universities are private corporations that should take whatever steps will prove most profitable. These views influence attitudes towards rankings. Some people consider that rankings are a market mechanism for consumer choice; others that they are an audit mechanism for taxpayer expenditure; others that they are an obstacle to egalitarian access to education.

Individuals who have no normative objection to rankings in principle, may nonetheless consider that they fail their purpose in practice. For example, they may be based on inaccurate or irrelevant data; or use inappropriate algorithms or arbitrary weightings (Marginson, 2014; Johnes, 2018); or be unstable to small changes in parameters or method (Adler \& Harzing, 2009; Saisana, d'Hombres, \& Saltelli, 2011); or suffer from positive feedback whereby higher ranked universities or courses receive more support (Gioia \& Corley, 2002; Rolfe, 2003). These issues are instrumental rather than normative.

Instrumental perspectives recognise that universities have existed for centuries, in many countries, and carry out all the functions above, to various degrees. They compete for funds and students in a "highly competitive, high-stakes game" (Gioia \& Corley, 2002), using a wide range of complex strategies. Third-party ranking systems exist, and are used by students, staff, employers, alumni, donors, and government agencies (Gioia \& Corley, 2002; Marginson, 2014; Johnes, 2018). Universities have no power to stop them, but can influence their rankings to some degree. Most stakeholders believe that rankings are imperfect but not random, and act as indicators of performance in areas that stakeholders consider relevant.

From a competitive-strategy or game-theory perspective (Osterloh \& Frey, 2015), university rankings are one component of a multi-tier, multi-player, global competitive game, a "game of academic prestige" (Adler \& Harzing, 2009), or "organisational status competition" (Brankovic, 2018). This is the principal theoretical perspective adopted in the current analysis. If you are in a game but do not recognise that the game exists, you will lose. Universities do indeed recognise that they are in this 
game, and play strongly (Espeland \& Sauder, 2007; Marginson, 2014). Many pretend not to (Willmott, 2011), but deceptive communications are part of many games.

Some analysts have written disparagingly of "gaming the system" (Gioia \& Corley, 2002, p. 113; Espeland \& Sauder, 2007, p. 29; Osterloh \& Frey, 2015), claiming that "game playing is morally dubious" (Clarke \& Knights, 2015, p. 1875). That is a normative view. The instrumental view is that if one can devise and use skills and strategies in any game, such as chess, poker, football, cricket, or competitive surfing, that give one an advantage whilst compliant with the rules of the game, then one is not "gaming the system", but simply playing the game well. Since universities are forced to compete fiercely for resources, the instrumental view is that they must recognise the importance of rankings, or fail.

Universities adjust strategies to reflect ranking systems

In practice, universities do indeed pursue rankings (Espeland \& Sauder, 2007; Johnes, 2018). They pursue multiple rankings systems concurrently, both national and international, government and private. Ranking organisations constantly adjust their data and algorithms (Marginson, 2014). The more finely-grained the ranking system, the greater the opportunities for universities to adjust their strategies. They can only do this, however, if they can identify what strategies will improve their ranks.

There are three approaches. First, universities can pursue the parameters explicitly listed by the rankings agencies, such as student satisfaction measures or top-tier publications. This is the only approach realistically available for global systems that rank entire universities. Second, they can pursue parameters that post-hoc analyses show to be highly correlated with allocated ranks, even where the ranking algorithm is invisible. Citations provide an example.

Third, they can: deconstruct the algorithm and reproduce the data, to replicate the rankings; convert indices to recognisable parameters such as numbers of publications in particular journals; calculate what specific strategies would improve their positions; and compare the risks and cost-effectiveness of each strategy. This is the approach followed here. It is not universally feasible. It has apparently been attempted only once, for a domestic ranking system of law schools in the USA (Espeland \& Sauder, 2007), but without published results. The current analysis thus appears to be the first successful attempt to use this approach.

Rankings in tourism

Since tourism and related fields were not recognised as an identifiable academic discipline until quite recently in the overall history of research, the first rankings within tourism were calculated by tourism researchers and published in tourism journals. This was valuable, since tourism journals were not initially included in $\mathrm{ISI}{ }^{\circledR}$ or Elsevier ${ }^{\circledR}$ lists of journal impact factors or rankings, or in the Science or Social Science Citation Indices ${ }^{\circledR}$. These published academic ranking exercises demonstrate that tourism researchers and journal editors do indeed ascribe value to rankings. There have been at least 20 published ranking exercises in tourism, and these continue to the present day. 
The largest proportion of these focussed on relative rankings of journals (Pechlaner, Zehrer, Matzler, \& Abfalter, 2004; McKercher, Law, \& Lam, 2006; Zehrer, 2007; Jamal, Smith, \& Watson, 2008; Hall, 2011; McKercher, 2012; Chang \& McAleer, 2012; McKercher \& Tung, 2015; Gursoy \& Sandstrom, 2016). A second group focussed on ranking authors (Sheldon, 1991; Ryan, 2005; McKercher, 2008; Li \& Xu, 2015; Zhao \& Ritchie, 2007) or universities (Jogaratnam, Chon, McCleary, Mena, \& Yoo, 2005). A smaller number searched for trends, patterns and networks in content and topic (Xiao \& Smith, 2006; Ballantyne, Packer, \& Axelsen, 2009; Benckendorff, 2009; Racherla \& Hu, 2010; Yuan, Gretzel, \& Tseng, 2015). A few, notably Park, Phillips, Canter, and Abbott (2011), addressed all of these simultaneously. Because these rankings were internal to the discipline itself, they received little recognition except from tourism researchers themselves.

Universities and governments focus heavily on national research assessment exercises, which directly influence government funding. The national framework in Australia, for example, known as Excellence in Research Australia (ERA), includes a tourism discipline ranking. The ERA tourism rankings, however, are generated from the opinions of expert panels, not computed from numerical data. Panel members can and do use publication data to form their opinions, but they are not required to follow any specific algorithm.

Students, staff and employers rely mainly on international rankings (Johnes, 2018), and universities advertise these actively. The three best-known international rankings are those by the Times Higher Education World University Rankings 2018 (THE) (2018), Quacquarelli Symonds Ltd (QS) (2018), and the Academic Ranking of World Universities (ARWU), carried out by the Shanghai Rankings Consultancy (2018a). Each of these include rankings for subject groups as well as overall. Of these three, only the AWRU contains a subject ranking category for tourism, hospitality, sport and leisure, and this was calculated for the first time in 2018 (Shanghai Rankings Consultancy, 2018b). The ARWU subject rankings are calculated at the scale of entire universities, not individual researchers.

Here, I deconstruct how these first ARWU tourism subject rankings were calculated, and identify implications for the future of tourism research. This deconstruction proves possible for four reasons, as follows. The ARWU tourism ranks are based only on publications. Tourism publication data from universities or individuals are available to analysts from the same source as used by the rankings agency. The ARWU weighting and calculation algorithm is relatively simple. Compared to many other disciplines, the global scale of tourism research is relatively small.

Methods

The ARWU rankings are of particular value for research, since they are based only on academic research outputs. Unlike THE and QS, ARWU do not include parameters related to teaching or administration, or surrogate input measures of research, such as grant income (Johnes, 2018). In addition, they rely principally on refereed journal articles, and they provide particular weight to the leading journals in each discipline, and additional weight to highly cited articles irrespective of journal. That is, they use essentially the same approach that academics use themselves (Marginson, 2014; Johnes, 2018). Even so, there are some complexities in the details of computation, outlined below.

The ARWU rankings for individual subjects are based on calculations of aggregate numerical indices, which are published along with the overall subject rankings (Shanghai Rankings Consultancy, 2018b), 
and the calculation methods (Shanghai Rankings Consultancy, 2018c). My first aim was to express these indices as recognisable academic parameters, such as numbers of publications. In order to achieve this, my first goal was to deconstruct the indices, using the published calculation approaches. The test of this deconstruction is the ability to reproduce the numerical indices. Initially, it proved impossible to reproduce the indices using only the published methods. Similar concerns have been raised and answered previously (Floria, 2007; Docampo, 2012), for an earlier iteration of the methodology.

My second step was to test that I was using the correct data, by contacting Clarivate Analytics (2018), the organisation that makes those data available via the proprietary system InCites ${ }^{\circledR}$. When this still did not reproduce the published indices, my third step was to contact the Shanghai Rankings Consultancy (SRC) staff. From this I learned of one additional calculation, not included in the published methods. The SRC staff kindly also provided answers to additional questions relating to interpretation of data on individual publications. I was then able to reproduce the indices, using different searches in InCites ${ }^{\circledR}$ to test different questions.

The data on which the ARWU rankings are based are lagged by several years from the date of publication. The 2017 rankings, published in 2018, are based on data for the five-year period 20112015 inclusive. Since data are already available up to 2017, the next two years' indices could also be calculated, even though they are not yet published by SRC. These cover the periods 2012-2016 and 2013-2017 respectively. My aim here, however, is not to preempt those numerical rankings, but to consider how the ranking process is likely to influence future tourism research.

To do this, I express the ARWU tourism-group aggregate subject scores in algorithmic form, and use local computational solutions to that algorithm to evaluate possible competitive strategies that closely-ranked universities could adopt to improve their positions. There is no universal algebraic solution, but the locally bounded computational approaches can provide strategies. I then consider, briefly and broadly, what types of investments would be required for each of these. Finally, I consider these strategies in the context of current demographics for tourism researchers. I show that this suggests a novel strategy, not currently adopted by any university, that could be used throughout the social sciences, and perhaps more broadly.

Results

How the ARWU Shanghai Rankings are calculated

The ARWU rankings use four or five different indicators, weighted differently for different subject groups. The four used for all disciplines are: "total" publications (PUB); "top" publications (TOP); mean category-normalised citation impact (Thompson Reuters, 2018), for those publications (CNCI); and proportion of publications with international coauthors (IC). For some disciplines, but not tourism, a fifth parameter is also used, namely number of awards such as the Nobel Prize or Fields Medal. For each indicator in each subject, the SR system first determines the highest-scoring university, and then normalises each other university's scores on that parameter against that highest score. Thus each university receives initial scores between 0.00 and 1.00 for the four parameters, and these are then multiplied by 100 for the published tables (Shanghai Research Consultancy, 2018b). These normalised parameter scores are then weighted and aggregated. The weightings for tourism are 1.5 for PUBS, 1.0 for TOT, 0.5 for $\mathrm{CNCl}$, and 0.1 for IC. 
The publication-related indicators are drawn from the proprietary database InCites ${ }^{\circledR}$, operated by Clarivate Analytics (2018). This is one of numerous publication databases now available. It originated, in pre-Internet times, as hard-copy publications from the Institute for Scientific Information ${ }^{\circledR}$, ISI, known as Current Contents ${ }^{\circledR}$ and Current Citations ${ }^{\circledR}$ respectively. ISI was later taken over by Thompson ISI, subsequently Thompson Reuters, which was then taken over by Clarivate Analytics. Its Web of Science ${ }^{\circledR}$ database was expanded to include social as well as natural sciences. Even this expanded database, however, includes only a rather restricted selection of journals. Indeed, many tourism researchers will recall when it added its first two tourism journals. Currently, it includes 45 journals in the tourism subject group. This also includes hospitality, sport and leisure journals, but only a selection of each. There are at least 80 tourism, leisure and hospitality journals alone, however (Scopus, 2018a), and more than 100 sports science journals (Scopus, 2018b); so clearly, InCites ${ }^{\circledR}$ uses only a specific subsample. Other publication databases, such as Google Scholar ${ }^{\circledR}$, Elsevier Scopus ${ }^{\circledR}$, Mendeley $^{\circledR}$, or ResearchGate ${ }^{\circledR}$, are either more comprehensive, or use different samples. These, however, are not used by ARWU.

InCites ${ }^{\circledR}$ classifies individual publications into various categories, and one of these is named Article. The ARWU parameters PUB and TOP are derived only from the Article classification. Precisely what Clarivate Analytics does and does not consider as an Article can be determined by comparing the InCites ${ }^{\circledR}$ "Article" publication lists for individual authors, against the overall publication lists for the same authors. These lists are available via different searches on InCites ${ }^{\circledR}$. It appears that broadly, the definition of Article used by InCites ${ }^{\circledR}$ is very similar to that used by the Australian HERDC Specifications, Higher Education Research Data Collection (Australia, Department of Education, 2018; Buckley, 2015). The HERDC Specifications require: publication, in print or online, in a reputable research journal; peer review; originality and addition to knowledge; and review of previous literature, with precedents and citations. Length is not a consideration, and nor is the title that any specific journal assigns to its various different types of publication item. Research notes and various types of opinion and commentary are thus counted as Articles, as long as they are peer reviewed and contain citations. Book reviews, and correspondence that is not peer reviewed and does not contain citations to previous research, are not counted.

This is straightforward in theory, but in practice there seems to be an anomaly. The definition of the Article category does not include book chapters. Article lists for individual universities, however, available in full via InCites ${ }^{\circledR}$, do indeed include some book chapters, apparently misclassified. This is similar to the Scopus database, which sometimes includes chapters in Elsevier books, though generally not books by other publishers. I asked the staff at Shanghai Rankings Consultancy whether they remove these book chapters manually, and they gave an equivocal answer. Recalculation of the actual published indices from InCites ${ }^{\circledR}$ data searches indicates that they do not: where InCites ${ }^{\circledR}$ includes book chapters in its Articles lists, these particular chapters are indeed included in PUB for the ARWU calculations. For the three highest-ranked universities during the 2011-2015 period, this misclassification of book chapters boosted PUB figures by $5-17 \%$.

The InCites ${ }^{\circledR}$ database uses the individual publication as the basic dataset unit. Parameters such as authors, author institutions, journal, journal subject category, journal impact factor, etc, are all linked to individual publications, and are not reclassified retrospectively. When authors move between institutions, InCites ${ }^{\circledR}$ tracks numbers of publications by that author from each individual institution. It can aggregate them by author, but it does not reassign them to the current institution. InCites ${ }^{\circledR}$ allocates each individual publication to a subject category on the basis of the journal where it was published. As noted earlier, InCites ${ }^{\circledR}$ does not include all the journals in any given subject 
category, but only a selection. This selection may change year by year. In tourism, it has gradually expanded.

InCites ${ }^{\circledR}$ does not consider keywords or titles to allocate publications to categories, only journals. An article published in an ecology journal, for example, is allocated to the ecology subject category, even if it is largely about tourism marketing (e.g., Buckley \& Mossaz, 2018). This contrasts with ranking systems such as the Australian ERA, where universities can reclassify some of their publications to different subject codes. For articles in multidisciplinary journals, such as Nature or PLoS ONE, InCites ${ }^{\circledR}$ allocates them according to the relative proportions of different subjects in each article's own reference list. An ecotourism article in PLOS ONE that cites more ecology references than tourism references, for example (e.g., Buckley, Morrison, \& Castley, 2016) is classified as ecology, whereas one that cites more tourism references (e.g., Romero-Brito, Buckley, \& Byrne, 2016) is classified as tourism.

For articles with multiple authors, the ARWU system does not use fractional counts, but allocates a full count to each of the institutions involved. Thus, a co-authored article where all authors are from the same university (e.g., Buckley et al., 2016) simply counts as one publication for that university. A co-authored article where the authors are from different universities, such as a research note with 52 authors from 41 universities (Hall et al., 2015) counts as one full publication for each university.

For the parameter TOP, the ARWU system counts publications from a specific set of high-ranked journals in each subject group. For tourism, these are defined as the top $20 \%$, by journal impact factor, of the journals in the InCites ${ }^{\circledR}$ tourism subject group. Since there are 45 such journals, the top $20 \%$ means the top 9 journals. These 9 can change from year to year, but currently include: the four top-ranked tourism journals; two sport psychology journals; and three hospitality journals. Any article counted within TOP also counts within PUB. Any article, research note, or refereed letter in Annals of Tourism Research, Tourism Management, Journal of Travel Research, or Journal of Sustainable Tourism counts twice, once in PUB with a weighting of 1.5, and again in TOP with a weighting of

1.0. This does not necessarily give it an overall weighting of 2.5 , because of the way in which the raw scores for each parameter are normalised before weighting and summing, as examined below.

The published description of the methodology (Shanghai Ranking Consultancy, 2018c) simply refers to a ratio between raw scores. If the world-leading university in PUB had published 100 articles, and the second had published 81 , this would indicate a ratio

0.81 for the latter. Advice from the SRC staff, however, is that it is not the linear ratio that is used, but the square root of that ratio. For the figures as above, therefore, the second-ranked university would actually be allocated a score of 0.90 , not 0.81 . These scores would be shown in the parameter tables (Shanghai Ranking Consultancy, 2018b) as 90 and 81 respectively. If only one parameter were used, this would not affect relative rankings. Since four parameters are used, however, each with a different weighting, this transformation can indeed affect the outcome. This is a key component of the methodology.

If we denote the raw counts for university i as $\mathrm{Pi}, \mathrm{Ti}, \mathrm{Ci}$, and li for $\mathrm{PUB}, \mathrm{TOP}, \mathrm{CNCl}$ and $\mathrm{IC}$ respectively, and the raw counts for the university with the highest count in each category as $\mathrm{P}^{*}, \mathrm{~T}^{*}, \mathrm{C}^{*}$, and $\mathrm{I}^{*}$, then the overall score for university i will be $\mathrm{Si}=\left[150 \mathrm{~V}\left(\mathrm{Pi} / \mathrm{P}^{*}\right)+100 \mathrm{~V}\left(\mathrm{Ti} / \mathrm{T}^{*}\right)+50 \mathrm{~V}\left(\mathrm{Ci} / \mathrm{C}^{*}\right)+10 \mathrm{~V}\right.$ $\left.\left(\mathrm{li} / /^{*}\right)\right]$. With hundreds of universities worldwide, and different universities scoring highest for different parameters, there is no overall algebraic solution for university $i$ to pick relative investments into $P, T, C$ and I so as to maximise $S$. We can, however, identify a number of general 
principles, and we can compare different strategies for universities with adjacent rankings, using local pairwise computational approaches. Since we already know the university scores both overall, and for each of the four individual parameters, for the 2011-2015 period, and we can calculate them for the two subsequent periods if we wish, this provides a basis to identify specific pairwise computations of greatest relevance and interest.

Converting scores to publication numbers

For the 2017 rankings based on 2011-2015 data, the 1st, 2nd and 3rd places overall were taken by Hong Kong Polytechnic University, HKPU, with an overall weighted score of 303; Griffith University, GU, 235; and the University of Queensland, $\cup Q, 233$. Both GU and UQ are in Australia. Ranks 4-10 inclusive were gained by universities in the UK and USA. HKPU scored 100 for PUB, 100 for TOP, and 90 for $\mathrm{CNCl}$. Corresponding figures for $\mathrm{GU}$ were 78, 71, and 77. For UQ the figures were 83, 66, and 70 respectively. The InCites ${ }^{\circledast}$ system allows us to extract Web of Science ${ }^{\circledR}$ publications by date, institution, document type (Article), and research field. Using this approach, for 2011-2015, InCites ${ }^{\circledR}$ says that HKPU produced total tourism articles (PUB) = 435, UQ 304, and GU 273.

For the two subsequent five-year brackets, $2012-16$ and 2013-17 respectively, InCites ${ }^{\circledR}$ shows HKPU tourism articles as 436 and 449, effectively stable at around 88 per year; UQ's at 290 and 276, a slight decline; and GU's as 297 and 379, a noticeable increase. The difference between 1st and 2nd place in PUB, for the 5-year bracket 2013-2017, was 70 articles over 5 years. This represents a mean difference of 14 per year, or about 3.3\%. This is quite a small difference. Over half of GU's count for the single year 2017 were actually book chapters, but even if these were removed, there would still be a noticeable increase. In recent years, $U Q$ has adopted an internal incentive strategy to encourage tourism staff to publish in the four top-tier tourism journals, so the decline in PUB may be counteracted by increases in TOP and $\mathrm{CNCl}$ : patterns for PUB alone do not necessarily predict the overall rankings.

I have not carried out full numerical calculations for all four parameters for the 2012-2016 and 2013-2017 brackets, since SRC may change its data sources, subject categories, methods, or parameter weightings before publishing the 2019 and 2020 rankings. Indeed, since the 2018 tourism subject rankings were the first iteration, it seems quite likely that the set of journals used for TOP and PUB may change; and indeed, that universities may lobby SRC for such changes. It is unlikely that the data sources, normalisation, transform, weightings or aggregation will change, since those are standard across all disciplines. Therefore, the effects of any changes in PUB or TOP are likely to be small and marginal. Here, therefore, I focus on general strategies that universities could adopt to boost their rankings, and consequences for tourism research and publication.

Analysis \& discussion: competition, constraints and consents

Key features of ARWU tourism subject rankings for university strategy

The overriding factor in the ARWU rankings system is the total number of active tourism researchers in each university. Ranks are calculated from total counts in the tourism subject group for the entire university, not per capita productivity. More productive academics generate larger numerical 
contributions, but these can be swamped by larger numbers of less productive academics. The first strategy for any university to improve its tourism subject ranking, therefore, is simply to increase the number of tourism researchers affiliated with that university and publishing under that affiliation.

The second key feature is that publications only count towards the ARWU tourism subject rankings if they are in one of the 45 InCites ${ }^{\circledR}$ tourism-group journals. This list may change year to year, but currently excludes a large number of tourism, sport, hospitality and leisure journals that are included, for example, in Google ${ }^{\circledR}$ Scholar ${ }^{\circledast}$ listings, rankings, and calculations such as $\mathrm{H}$ indices. Therefore, it would be a good strategy for universities to ensure that their academic staff are aware of this list and encouraged to use it preferentially, bearing in mind that new journals are added each year. Indeed, we can predict which new journals are most likely to be added, depending on impact factors, and lobbying by their publishers.

Third, all types of refereed publication in these 45 journals, notably including Research Notes, refereed Commentaries, and refereed Letters, count as Articles within InCites ${ }^{\circledR}$ and hence the Shanghai Rankings. It is to each university's advantage for each academic to maintain a portfolio of academic publications of different types, not only full-length original research articles. Therefore, internal university incentives, such as performance management measures, should count Research Notes and similar publication types equally to full-length articles. If they do not, that will disadvantage the university concerned.

Fourth, co-authorships with other universities do not dilute counts, and international co-authorships add a small extra score. In addition, if multiply-coauthored publications regularly achieve higher category-normalised citation impacts, as does occur in at least some disciplines (Valderas, Bentley, Buckley, \& Wray, 2007), then they will achieve higher scores again. The same applies if they are more likely to be accepted in TOP tourism-group journals. So working with international colleagues is a plus, on many counts.

Fifth, articles in top-four tourism journals, or in top-three hospitality or top-two sport psychology journals, score approximately

1.7 times more than those in non-TOP journals, because they count both in PUB at weight $1.5 \times$, and TOP at 1.0x. The ratio is not exact, because of the calculation algorithm as above, but it indicates that two articles in lower-ranked journals contribute more to a university's tourism-group subject ranking than one in a TOP journal. Universities should therefore encourage academics to publish in top-tier journals where possible, and if not, to double their outputs in lower-tier journals.

Value per publication: arbitrage, trading, and pay-per-publication models

A single publication contributes more to the ARWU score for a lower-ranked university than to a higher-ranked one. Suppose, for example, that the largest number of tourism-group publications by any university over a five-year period is 500 , so that $P^{*}=500$. Suppose that the count for the second-ranked university, $\mathrm{P} 2$, is 405 . The unweighted PUB scores, including the square root transformation as above, are therefore 100 and 90 respectively. If the top-ranked university publishes one more article, bringing its total count to 501 , then it will still score 100 , but the second-ranked will now score 89.91 , a reduction of 0.09 or $0.10 \%$. If, instead, the second-ranked university publishes one more article, then the top-ranked will still score 100 , but the second-ranked will now score 90.11 , an increase of 0.11 or $0.12 \%$. 
The greater the differential between the two initial scores, the greater the relative marginal differential contributed by one new publication from the second rather than first ranked university. Similar considerations apply for pairwise comparisons between, e.g., the second- and third-ranked universities, or any other combination. If an additional publication also counts in TOP, or scores well in $\mathrm{CNCl}$, that adds to the marginal differential. Likewise, if there is no change to the publication output of the highest-ranked university, but we consider one more publication added to the outputs of either the second-ranked or the third-ranked university, the proportional contribution is greater for the lower-ranked institution.

Are such small differentials of any significance? Yes indeed. These calculations are for one single article. Some individual tourism researchers publish 50 or more articles in a five-year period. More importantly, in subjects such as tourism where there is no significant investment in laboratory equipment or similar research infrastructure, the production cost per publication (Buckley, 2015) is effectively the same for any university in the same country, irrespective of its ranking. So at least in theory, tourism publications represent a commodity that can be produced at the same price in two or more universities, but is worth different amounts to those same universities. This presents opportunities for arbitrage.

In a (hypothetical) fully informed, fully clearing market with zero transaction costs, we could envisage a situation where the third- ranked university could buy just enough publications from the first-ranked university so as to overtake the second-ranked, but without reducing the first-ranked's output so far as to drop it into second place. Equally, the 2 nd or 3 rd might buy publications from a lower-ranked university, so as to put it into contention for 1st, whilst the lower-ranked university puts the money into boosting its ranking in another discipline entirely. The top-ranked university might buy publications from a low-ranked university, to protect its lead.

Such calculations and purchases would involve some effort and investment, but these would be small compared to the time, effort, and money that universities already invest into calculating how many students to offer places to, each year, in each of hundreds or thousands of individual courses. Each student has a different school-leaving score, in a format depending on country and jurisdiction. Each student brings a different amount of money, depending on the course and how the students are funded. Universities have limits on how many students they can accept in each field, because of facilities, staff, government funding rules, and so on. Within these constraints, they aim to optimise income and reputation, as defined by school-leaving scores for each course, in competition with other universities offering the same courses in the same student catchment. Arbitrage of publication outputs would be a simple task in comparison. Since ARWU ranks are a major contributor to reputation and hence student demand, the investment would be well justified.

Publication trading, purchase, and arbitrage do not yet occur directly, despite these incentives, because the assumptions of information, clearing, and free transactions have not yet been met. It does occur indirectly, and we may predict that this will increase as information becomes more readily available and more detailed. Transaction costs are low, since the author simply lists a different institutional address on the publication concerned. This decision must be made early in the publication process, which means that universities would need to project their outputs some years in advance, a limit to full information. This, however, is not the main obstacle. The principal barrier is the lack of a market for buying and selling publications, because of constraints set by government funding agencies, national assessment systems, and universities themselves. Next, therefore, I examine strategies that universities could or already do adopt to improve competitive positions in tourism research, and consider feasibility, consequences, ethical constraints, and the need, if any, for active consent by specific stakeholders. 
Current practices within individual universities

Information on strategies and practices within individual universities is available only at coarse resolution. We can see what universities do, but not why. For example, we can see when they advertise for new tourism staff, or announce new tourism courses. Within our own universities, we can see when they allocate internal resources preferentially to tourism, or preferentially to other disciplines. For example, they may create, upgrade, downgrade, or abolish tourism research centres. They may co-fund grant bids, or appoint support staff, or refuse to do so. They may reward researchers for tourism publications, eg through payment of cash bonuses, or per-publication research grants, or by allocating government publication-performance funds to the individuals who earned them. Alternatively, they may withhold all of these, and effectively punish tourism researchers by allocating funds preferentially to competing fields, and discounting tourism publications in performance assessments. Such strategies may not be either explicit or consistent. Different parts of the same university may reward or punish tourism at the same time.

For the universities currently holding the top 3 positions in the ARWU rankings, the relative importance of tourism would appear to be greatest for HKPU, which has invested in its own hotel. UQ and Griffith have allocated resources to tourism at times, but these were small in comparison to, e.g., medicine. Their current strategies seem to reflect concern over domestic ERA ratings. Both Griffith and UQ have higher ARWU rankings in tourism than any other subject, however, and best opportunities to get to world \#1 with lowest cost. Similar incentives apply for the UK and US universities with ARWU tourism rankings 4-10. Next, therefore, I consider how they might use the various approaches outlined above.

Timing, granularity, data, and algorithms

The primary data unit in the inCites database is the individual publication. Date, authors, journal, and institutional affiliations are recorded as parameters attached to that unit. As soon as a new publication is included in inCites, it is available for ARWU calculations. Universities could therefore calculate their subject scores, and those of competitors, well ahead of the official ARWU listings typically, two years earlier. Indeed, if data extraction and calculation were automated, with currentyear figures adjusted to whole- year estimates, it would be possible to generate ARWU scores moment-by-moment in stock-ticker format.

Since the raw data are publicly available, there would not seem to be any ethical barriers to this. It would enable academic managers to track the relative performance of their tourism research groups, and decide whether to adjust their resource allocations. It would not provide any avenue to influence the official ARWU scores before they are released, since publication parameters are fixed at the time of publication, but it would overcome the current information lag of two or more years. It is possible that the Shanghai Rankings Consultancy might modify their algorithm in the meantime, but this is unlikely, since the same algorithm applies across all academic disciplines.

Currently, ARWU rankings are released at two scales or granularities: entire universities, and subject groups within universities. With the incites data and the SRC algorithm, it would now be possible to 
calculate approximate contributions of individual academics to their universities' tourism subject rankings. Because of the normalisation step for each parameter prior to transformation and weighting, these would only be approximations. Research rankings of individual tourism academics have been calculated previously (Sheldon, 1991; Ryan, 2005; McKercher, 2008; Li \& Xu, 2015), and other measures such as $\mathrm{H}$-indices are available via Google Scholar ${ }^{\circledast}$, but contributions to the recognised high-prestige ARWU ranks have not previously been available. If previous published individual rankings are considered ethical, the same should presumably also apply for individual ARWU rankings.

Equally, it would be possible to make equivalent calculations at coarser granularity, for entire countries. These could be used to influence education policy, eg as regards institutional amalgamations, national subject-scale hubs or institutes, or bilateral purchase or trade of publications or fractional appointments. These options are considered further below.

Finally, although individual academics or universities have little influence on the methodologies adopted by the Shanghai Rankings Consultancy, they could run their own analyses to quantify the sensitivities of rankings to different publication data sources, parameter weightings, or normalisation and aggregation algorithms. The results would not have the political power of the published ARWU subject rankings, but they could be compared against previously published discipline-based rankings (Jogaratnam et al., 2005; Park et al., 2011). They might be used to lobby SRC for modifications, eg to weightings.

Existing indirect mechanisms for publication transfers between universities

Differences in subject rankings between universities can now be expressed, approximately, in numbers of publications per year, either in top-ranked journals or in all inCites-listed journals. These numbers are imprecise, because rankings also depend on category- normalised citation indices and on international co-authorship. They are sufficiently accurate to show, however, whether or not any university could reasonably expect to achieve a higher ARWU tourism subject ranking. If so, then it can invest in boosting publications, with known targets.

There are many mechanisms to boost publications. Universities can appoint new staff, either as fulltime tenured staff, or part- time, or short-term contract research fellows, or as emeritus, adjunct, or visiting staff. These are a normal part of university operations. Many researchers hold adjunct appointments at multiple universities, in the same or different countries, and list some or all affiliations on different publications. The institutions offer incentives, and claim rewards via rankings. Other variants include split salaries, salaries paid through multi-institution grants, and part-year or fractional full-time appointments.

Visiting appointments are also funded by governments, eg through grants to work at overseas institutions. Conditions may include requirements for publications and listed affiliations. These are considered entirely ethical, despite co-authorship issues considered below. Both originating and host institutions, and individual visiting and host academics, are required to consent to these arrangements before they commence operations. 
There has been substantial recent discussion about the ethics of academic coauthorship (Adler \& Harzing, 2009; Sikes, 2009; Kovacs, 2012), including coauthor and cross-citation cartels (Van Noorden, 2013), and honorary coauthorship. The direct publication purchase proposals put forward here would not affect any of the current coauthorship rules and incentive structures. Existing indirect mechanisms involving visiting appointments do create one concern. Universities may offer their own academic staff internal grants for collaborative publication with external coauthors. These may attract external researchers to offer coauthorships to academic colleagues at those universities, for research that would not otherwise generate coauthor rights.

Many universities offer visiting chairs or fellowships, in a range of academic disciplines, with a requirement for the visitor to coauthor a publication with their nominated host. Where these visits are too brief to conduct new joint research, these fellowships are effectively a mechanism to buy external publications, using fellowship funds to purchase an institutional affiliation for the visiting academic, an honorary coauthorship for the host academic, or both. This mechanism already operates, without universities buying and selling publications directly, and without offering either fractional, emeritus, or adjunct appointments to external tourism re-searchers. It is considered ethically acceptable.

Proposed direct publication purchases between universities or independent authors

The mechanism proposed here, but not yet in use, is the direct open purchase of publications, either from academic staff employed by other universities, or from retired or otherwise independent authors. In the former case, payment would presumably be from university to university; in the latter, university to individual. In the former case, both universities, and the individual, would have to consent in advance to the arrangement, since the individual author would need to list the purchasing university affiliation when submitting the manuscript. Details of financial arrangements, and at least an adjunct or visiting affiliation for the author, would also have to be agreed in advance, in either case.

Would there be any ethical barriers to such arrangements? Many academics, in tourism as in other disciplines, already list multiple institutional affiliations on their publications. These may include fractional, emeritus or adjunct, and visiting affiliations, which may involve various forms of remuneration in cash or in kind. That is, the proposal here would merely formalise, clarify, and expand the scale of a longstanding existing practice. It would not change the actual research conducted, or the journals in which it is published.

Making publication purchase an open practice would create an opportunity for publication brokerages, where brokers could routinely calculate institutional costs and gains of specific trades, and approach universities and individuals concerned with proposals to negotiate arrangements in return for commissions. Brokers are ethically acceptable in insurance, property, shares, even conservation easements. Why not in academic publications?

Publication purchases, as proposed here, are for externally written articles. They are quite distinct from incentive payments for publications by existing employees, which are widespread and widely debated (Fuyuno \& Cyranoski, 2006; Franzoni et al., 2011; Abritis, McCook, \& Watch, 2017). Universities provide a wide variety of internal incentives in different disciplines, most of them 
inequitable. Favoured faculties or research groups already get better facilities, higher salaries, more support, and lower teaching loads. Publication purchases would not affect any of these factors. They would provide funds that selling universities could use to boost support for the academics concerned, increasing equity.

The cohort of recently retired tourism professors

In the particular case of tourism, it so happens that there is a substantial demographic group of tourism professors, either recently retired or about to retire, still productive in research publication, but no longer on the salaried staff of any university. Effectively, they are free to sell their publications to the highest bidder. Any university that wants to take advantage of this opportunity merely has to offer visiting, adjunct or emeritus positions to such professors, and pay them per accepted publication.

For retired professors, or any other independent tourism researcher, there is no reason why universities could not pay a contract fee per publication. That is, the universities would be subcontracting independent researchers to conduct and publish research, paid on completion. Of course, since the fees would have to cover time, and the risk of publication rejection, as well as expenses, the price per publication would be considerably greater than the bonuses currently paid to existing salaried staff. These prices could still be considerably less, however, than the current total average production cost per publication achieved by full-time salaried academic staff, which is around 2018 US\$150,000 (Buckley, 2015). That is, the universities would do well financially from such arrangements. Many universities, especially those already well ranked in tourism, do already maintain a "stable" of retired professors in adjunct or emeritus positions. But they do not, it seems, pay them per publication, so many are not very productive. The number of potentially available, highly productive, retired or retiring tourism, hospitality and sport professors worldwide is limited. Most of them can work from anywhere. Any university aiming to achieve or retain world 1st rank in tourism research could negotiate with as many as possible, as soon as possible, to secure arrangements to buy future publications at predetermined prices. Of course, if they also want exclusivity, they would need to expect to pay either a premium per publication, or a retainer. All of these approaches are entirely

standard in many commercial professions. Why not in tourism research?

Purchasing publications from retired or otherwise independent academic authors involves different ethical considerations than purchases between universities. Professionals in other fields do not work for free; and nor do retired academics acting as consultants. If retired professors are prepared to enter publication contracts paid on completion, it is they who bear the risk, not the universities. If retired professors apply their time and expertise to conducting and publishing research for a specific university, it would be ethical for that university to pay them, and unethical not to do so.

Purchasing publications from retirees would shift part of universities' research load onto nonsalaried contractors. Would this mean fewer tenured appointments for younger staff? This could create an indirect ethical concern over equity. It seems unlikely, however, since tenured positions are created principally for teaching, even if applicants are judged on their research. Most researchonly positions are short-lived contracts. Indeed, if buying publications from retired professors boosts rankings, that may generate more new positions for younger staff. 
Competition between countries

At national scale, countries adopt education policies and regulations that enhance their competitive positions relative to other countries, to attract a greater share of the international tertiary education export market (Dill \& Soo, 2005; Bougnol \& Dula, 2006; Espeland \& Sauder, 2007; Ehrenberg, 2012; Johnes, 2018). They fund higher-ranked universities preferentially, and they introduce legislation and funding measures to encourage formation of multi-university national research consortia. In some countries, they encourage amalgamation of universities (Johnes, 2018). Historically, they have taken such measures without being able to calculate how they would affect rankings such as ARWU. Now they can indeed make such calculations. Each country could calculate its overall rank, if some or all of its universities were combined.

Countries could fund their leading universities, in tourism or other subjects, to purchase publications from lower-ranked universities. They could also purchase publications from universities in other countries, if those other countries and universities allowed it. This would provide a considerable international competitive advantage. The mechanisms would be the same as for bilateral trades and purchases. Universities and individuals involved would have to grant consent in advance, and individuals would have to gain some kind of affiliation to the hub university, and list it on their manuscripts.

Ethical considerations for individuals would seem to be the same as for bilateral trades or purchases between universities. Academics employed at universities which do not rank highly in tourism, would be able to gain research funds by allowing their universities to sell their publications to those that do. That would enhance equity. Larger countries would enjoy an advantage in rankings, but they have that already. Countries with numerous low-ranked universities could outcompete countries with few high- ranked universities, but universities also keep their individual ranks.

At national level, some countries have already adopted the strategy of amalgamating entire universities, so as to boost global rankings that depend on scale (Bekhradnia, 2016; Gérand, 2016; Johnes, 2018). Since the 2018 ARWU rankings were published, two Australian universities have announced their intention to merge, specifically to retain a top-100 rank (Bousvert, 2018). Many countries, including the UK, USA, and Australia, also operate multi-campus universities under a single name, with the University of California as one well-known example. Both GU and UQ are also multi-campus universities, though not all campuses include tourism researchers. There appear to be no ethical objections to the scale or geographical structure of universities, either large or small.

\section{Conclusions}

The introduction of the tourism-group subject ranking in the 2018 ARWU has created a new pressure on the practical administration, management and funding of tourism research within universities, considerably more powerful than rankings published previously in academic journals (Jogaratnam et al., 2005; Park et al., 2011). Indeed, it has been argued that international rankings exert a more powerful force on universities, than the laws of individual nations (Kehm, 2014; Marginson, 2014; Johnes, 2018). 
The ARWU tourism ranking shows that tourism has now earned recognition as a field of research equal to any of the other ranked subjects. This will force universities to pay substantially more attention to tourism in the future. Since tourism research is still a smaller field worldwide than many other disciplines with their own ARWU subject rankings, opportunities to improve rankings involve less inertia than other disciplines. Since the ARWU rankings cover a five-year bracket and are lagged by two or more years, however, only those universities that are already ranked highly in tourism research can take advantage of this new opportunity.

The ARWU tourism subject ranking will create new pressures for Universities to boost their publication outputs in five different ways, not mutually exclusive: (a) across tourism, hospitality, sport and leisure jointly; (b) within the 45 journals included in the InCites ${ }^{\circledR}$ tourism group specifically; (c) within the 4 top tourism journals, 3 top hospitality journals, and 2 top sport psychology journals preferentially; (d) across all refereed publication categories classified by InCites ${ }^{\circledR}$ as Articles, which includes refereed re- search notes, commentaries, letters and opinions with citations and novel insights; and (e) with multiple coauthors, especially from other universities and other countries, to boost likely category-normalised citation impact and international co-authorship scores. Pressure to produce highly-cited individual publications already exists and will not change.

All these will create financial incentives, and hence pressures to create practical mechanisms, to allow publications to be traded between universities, both nationally and internationally. There will be national-scale advantages for any country that establishes such a mechanism. Currently, there is nothing to prevent individual universities negotiating arrangements for listed affiliations on individual articles, via fractional, adjunct or visiting appointments, so that publications are assigned to the university where they have greatest value. If universities decided to adopt this approach, that would create a market for a form of publication arbitrage, where private brokers can calculate relative values of research publications to different universities, and negotiate sale and purchase in return for commissions.

In tourism specifically, there is a current, and perhaps brief, opportunity for universities to contract retired academics or in- dependent tourism researchers on a pay-per-publication basis. This would be substantially cheaper than hiring additional full-time staff. It would boost those universities' tourism publication outputs enough to change their relative positions in the ARWU tourism rankings.

If these approaches work well in tourism, could they be applied to university research worldwide? We are already seeing the delivery of teaching move from a very immediate and individualistic style, where each lecturer created their own lectures just in time, to a much more centralised approach, with multi-year multi-media materials produced by global publishers. It will only be a small step for every course to be assessed through a set of internationalised micro-credentials. And from there, it may not be long until coursework providers offer their own degrees; and indeed, until a degree from such a global provider becomes worth more than one from any but the highest-ranked individual universities.

If that happens to teaching, why not research? Historically, high-cost research in science and medicine has been based around individual laboratories, where academics apply for a long series of government research grants until they accrue enough equipment, money and staff to conduct world-leading research. Currently, however, large laboratories are increasingly owned by consortia, and governments prefer to fund group facilities. How long until the labs are run by private companies that hire them to universities as needed? And either the labs, or the universities, hire researchers and pay them a retainer plus per-publication fees? 
There are many arguments against such approaches, including safety, academic reliability, poor maintenance by cash-strapped private operators, and more. None of those barriers, however, have prevented such models operating in high-cash industries such as defence or pharmaceuticals. It might be more difficult for them to operate in low-cash industries such as public health, environment, or tourism; but by no means impossible. The structure of university teaching and research is changing, as a result of social change and technological innovations; and this changes the relationships between university prestige and power.

The inclusion of replicable subject rankings in the 2018 ARWU, at least in tourism, can thus provide a range of new perspectives on power and prestige within universities, likely to yield some significant practical short-term responses. Refereed research publications may be seen as commodities, tradeable between universities, and purchasable from retired professors or other independent researchers. Direct purchase mechanisms could complement and expand current indirect mechanisms to achieve the same ends, via fractional, emeritus, adjunct, and visiting appointments. International competition between countries, as well as individual universities, creates a strong incentive to pursue this option. It seems to lie well within current ethical and financial envelopes for tertiary education. It could start immediately.

Tourism provides a test case in this regard, because the numerical deconstruction and replication of the rankings is feasible, and because most tourism researchers do not need large laboratories. If universities do pursue these approaches, it may represent one step towards a gig-economy redesign of research. That would have broader normative implications both for the epistemology of tourism knowledge, and the social role of universities. In particular, it might modify the balance of power and prestige between individual researchers, and the universities that hire them. There are already substantial inequities between disciplines, in working conditions and remuneration. Perhaps the position of tourism may be enhanced by the factors examined here. I look forward to further analysis of all these aspects.

\section{Acknowledgements}

My thanks to staff of the Shanghai Rankings Consultancy, Clarivate Analytics, and Griffith University Office for Research, for provision of technical information and assistance. 
References

Abritis, A., McCook, A., \& Watch, R. (2017). Cash incentives for papers go global. Science, 357, 541.

Adler, N. J., \& Harzing, A. W. (2009). When knowledge wins: Transcending the sense and nonsense of academic rankings. Academy of Management Learning \& Education, 8, 72-95.

Australia, Department of Education and Training, 2018. 2018 Higher Education Research Data Collection: Specifications for the Collection of 2017 Data, https://docs.education.gov.au/system/files/doc/other/final_2018_herdc_specifications_0.docx.

Ballantyne, R., Packer, J., \& Axelsen, M. (2009). Trends in tourism research. Annals of Tourism Research, 36, 149-152.

Benckendorff, P. (2009). Themes and trends in Australian and New Zealand tourism research: A social network analysis of citations in two leading journals (1994-2007). Journal of Hospitality and Tourism Management, 16, 1-15.

Bekhradnia, B., 2016. International university rankings: For good or ill? Higher Education Policy Institute. http://www.hepi.ac.uk/wp-content/uploads/2016/12/ Hepi_International-universityrankings-For-good-or-for-ill-REPORT-89-10_12_16_Screen.pdf.

Brankovic, J. (2018). The status games they play: Unpacking the dynamics of organisational status competition in higher education. Higher Education, 75, 695-709. Brosnan, C. (2016). Bourdieu and the future of knowledge in the university. Bourdieusian Prospects (pp. 61-82). London: Routledge.

Bougnol, M. L., \& Dula, J. H. (2006). Validating DEA as a ranking tool: An application of DEA to assess performance in higher education. Annals of Operations Research, 145, 339-365.

Bourdieu, P. (1979). La Distinction: Critique Sociale du Jugement. Paris: Minuit.

Bousvert, E., 2018. University of Adelaide and UniSA to explore potential merger to create new institution. http://mobile.abc.net.au/news/2018-06-19/sa- universities-to-discuss-potentialmerger/9885996.

Bøyum, S. (2014). Fairness in education-a normative analysis of OECD policy documents. Journal of Education Policy, 29, 856-870. Buckley, R. C. (2015). Please be more specific. Campus Review, 25(5), 17.

Buckley, R. C., Morrison, F. C., \& Castley, J. G. (2016). Net effects of ecotourism on threatened species survival. PloS ONE, 11, e0147988.

Buckley, R. C., \& Mossaz, A. (2018). Private conservation funding from wildlife tourism enterprises in sub-Saharan Africa: Conservation marketing beliefs and practices. Biological Conservation, 218, 5763.

Chang, C.-L., \& McAleer, M. (2012). Citations and impact of ISI tourism and hospitality journals. Tourism Management Perspectives, 1, 2-8. Clarivate Analytics, 2018. InCites. An Objective Analysis of People, Programs and Peers. https://clarivate.com/products/incites/.

Clarke, C. A., \& Knights, D. (2015). Careering through academia: Securing identities or engaging ethical subjectivities? Human Relations, 68, 1865-1888. De Fraja, G., \& Valbonesi, P. (2012). The design of the university system. Journal of Public Economics, 96, 317-330. 
Desrochers, N., Paul-Hus, A., Haustein, S., Costas, R., Mongeon, P., Quan-Haase, A., ... Larivière, V. (2018). Authorship, citations, acknowledgments and visibility in social media: Symbolic capital in the multifaceted reward system of science. Social Science Information, 57, 223-248.

Dill, D. D., \& Soo, M. (2005). Academic quality, league tables, and public policy: A cross-national analysis of university ranking systems. Higher Education, 49, 495-533. Docampo, D. (2012).

Reproducibility of the results of the Shanghai academic ranking of world universities. Scientometrics, 94, 567-587.

Eco, U. (1988). Foucault's Pendulum. London: Harcourt Brace Jovanovich.

Ehrenberg, R. G. (2012). American higher education in transition. Journal of Economic Perspectives, $26,193-216$.

Espeland, W. N., \& Sauder, M. (2007). Rankings and reactivity: How public measures recreate social worlds. American Journal of Sociology, 113, 1-40. Floria, R. V. (2007). Irreproducibility of the results of the Shanghai academic ranking of world universities. Scientometrics, 72, 25-32.

Foucault, M. (1966). Les Mots et les Choses. Paris: Garimard.

Franzoni, C., Scellato, G., \& Stephan, P. (2011). Changing incentives to publish. Science, 333, 702703. Fuyuno, I., \& Cyranoski, D. (2006). Cash for papers: Putting a premium on publication. Nature, 441, 792. Gérand, C., 2016. Aix-Marseille, laboratoire de la fusion des universités. www.mondediplomatique.fr.

Giacalone, R. A. (2009). Academic rankings in research institutions: A case of skewed mind-sets and professional amnesia. Academy of Management Learning \& Education, 8, 122-126.

Gioia, D. A., \& Corley, K. G. (2002). Being good versus looking good: Business school rankings and the Circean transformation from substance to image. Academy of Management Learning \& Education, 1 , 107-120.

Gruber, T. (2014). Academic sell-out: How an obsession with metrics and rankings is damaging academia. Journal of Marketing for Higher Education, 24, 165-177. Gursoy, D., \& Sandstrom, J. K. (2016). An updated ranking of hospitality and tourism journals. Journal of Hospitality \& Tourism Research, 40, 3-18.

Hall, C. M. (2011). Publish and perish? Bibliometric analysis, journal ranking and the assessment of research quality in tourism. Tourism Management, 32, 16-27. Hall, C. M., Amelung, B., Cohen, S., Eijgelaar, E., Gössling, S., Higham, J., ... Aall, C. (2015). Denying bogus skepticism in climate change and tourism research. Tourism

Management, 47, 352-356.

Hands, D. W. (2012). The positive-normative dichotomy and economics. Handbook of the Philosophy of Science, 13, 219-239. Hicks, D. (2012). Performance-based university research funding systems. Research Policy, 41, 251-261.

Himanen, L., Auranen, O., Puuska, H. M., \& Nieminen, M. (2009). Influence of research funding and science policy on university research performance: A comparison of five countries. Science and Public Policy, 36, 419-430.

Jamal, T., Smith, B., \& Watson, E. (2008). Ranking, rating and scoring of tourism journals: Interdisciplinary challenges and innovations. Tourism Management, 29, 66-78. 
Jogaratnam, G., Chon, K., McCleary, K., Mena, M., \& Yoo, J. (2005). An analysis of institutional contributors to three major academic tourism journals: 1992-2001.

Tourism Management, 26, 641-648.

Johnes, J. (2018). University rankings: What do they really show? Scientometrics, 115, 585-606.

Kehm, B. M. (2014). Global university rankings: Impacts and unintended side effects. European Journal of Education, 49, 102-112.

Kovacs, J. (2012). Honorary authorship epidemic in scholarly publications? How the current use of citation-based evaluative metrics make (pseudo) honorary authors from honest contributors of every multi-author article. Journal of Medical Ethics medethics-2012.

Li, J., \& Xu, Y. (2015). Author analyses of tourism research in the past thirty years-Based on ATR, JTR and TM. Tourism Management Perspectives, 13, 1-6. Marginson, S. (2014). University rankings and social science. European Journal of Education, 49, 45-59.

McKercher, B. (2012). Influence ratio: An alternate means to assess the relative influence of hospitality and tourism journals on research. International Journal of Hospitality Management, 31, 962-971.

McKercher, B. (2008). A citation analysis of tourism scholars. Tourism Management, 29, 1226-1232.

McKercher, B., Law, R., \& Lam, T. (2006). Rating tourism and hospitality journals. Tourism Management, 27, 1235-1252.

McKercher, B., \& Tung, V. (2015). Publishing in tourism and hospitality journals: Is the past a prelude to the future? Tourism Management, 50, 306-315.

Muller, S. M. (2017). Academics as rent seekers: Distorted incentives in higher education, with reference to the South African case. International Journal of Educational Development, 52, 58-67.

Nkomo, S. M. (2009). The seductive power of academic journal rankings: Challenges of searching for the otherwise. Academy of Management Learning \& Education, 8, 106-121.

Osterloh, M., \& Frey, B. S. (2015). Ranking games. Evaluation Review, 39, 102-129.

Parisi, F. (2004). Positive, normative and functional schools in law and economics. European Journal of Law and Economics, 18, 259-272.

Park, K., Phillips, W. J., Canter, D. D., \& Abbott, J. (2011). Hospitality and tourism research rankings by author, university, and country using six major journals: The

first decade of the new millennium. Journal of Hospitality \& Tourism Research, 35, 381-416.

Pechlaner, H., Zehrer, A., Matzler, K., \& Abfalter, D. (2004). A ranking of international tourism and hospitality journals. Journal of Travel Research, 42, 328-332. Peng, S., Yang, A., Cao, L., Yu, S., \& $X i e$, D. (2017). Social influence modeling using information theory in mobile social networks. Information Sciences, 379, 146-159. Porter, M. E. (2011). Competitive advantage of nations: Creating and sustaining superior performance. New York: Simon and Schuster.

Quacquarelli Symonds Ltd., 2018. QS World University Rankings, https://www.topuniversities.com/university-rankings/world-university-rankings/2018. Racherla, P., 
\& Hu, C. (2010). A social network perspective of tourism research collaborations. Annals of Tourism Research, 37, 1012-1034.

Rizvi, F., \& Lingard, B. (2009). Globalizing education policy. London: Routledge.

Rolfe, H. (2003). University strategy in an age of uncertainty: The effect of higher education funding on old and new universities. Higher Education Quarterly, 57, 24-47.

Romero-Brito, T. P., Buckley, R. C., \& Byrne, J. (2016). NGO partnerships in using ecotourism for conservation: Systematic review and meta-analysis. PloS ONE, 11

e0166919.

Ryan, C. (2005). The ranking and rating of academics and journals in tourism research. Tourism Management, 26, 657-662.

Scopus, 2018a. Journal Rankings: Tourism, Leisure and Hospitality Management. https://www.scimagojr.com/journalrank.php?category=1409. Scopus, 2018b. Journal Rankings: Sport Science. https://www.scimagojr.com/journalrank.php?category=3699.

Shanghai Ranking Consultancy (2018a). Academic Ranking of World Universities 2017. http://www.shanghairanking.com.

Shanghai Ranking Consultancy (2018b). ShanghaiRanking's Global Ranking of Academic Subjects 2017 - Hospitality \& Tourism. http://www.shanghairanking.com/ Shanghairanking-SubjectRankings/hospitality-tourism-management.html.

Shanghai Ranking Consultancy (2018c). Methodology for ShanghaiRanking's Global Ranking of Academic Subjects 2017. http://www.shanghairanking.com/ Shanghairanking-SubjectRankings/Methodology-for-ShanghaiRanking-Global-Ranking-of-Academic-Subjects-2017.html. Saisana, M., d'Hombres, B., \& Saltelli, A. (2011). Rickety numbers: Volatility of university rankings and policy implications. Research Policy, 40, 165-177. Sheldon, P. J. (1991). An authorship analysis of tourism research. Annals of Tourism Research, 18, 473-484.

Shin, J. C., Toutkoushian, R. K., \& Teichler, U. (Eds.). (2011). University rankings: Theoretical basis, methodology and impacts on global higher education. Dordrecht: Springer.

Sikes, P. (2009). Will the real author come forward? Questions of ethics, plagiarism, theft and collusion in academic research writing. International Journal of Research \& Method in Education, $32,13-24$.

Thompson Reuters (2018). Category Normalized Citation Impact. http://ipsciencehelp.thomsonreuters.com/inCites2Live/indicatorsGroup/aboutHandbook/ usingCitationIndicatorsWisely/normalizedCitationImpact.html.

Times Higher Education Magazine, 2018. Times Higher Education World University Rankings 2018. https://www.timeshighereducation.com/world-university- rankings.

Valderas, J. M., Bentley, R. A., Buckley, R. C., \& Wray, K. B. (2007). Why do team-authored papers get cited more? Science, 317, 1496-1498. Van Noorden, R. (2013). Brazilian citation scheme outed.

Nature, 500, 510-511.

Willmott, H. (2011). Journal list fetishism and the perversion of scholarship: Reactivity and the ABS list. Organization, 18, 429-442. 
Xiao, H., \& Smith, S. L. (2006). The making of tourism research: Insights from a social sciences journal. Annals of Tourism Research, 33, 490-507.

Yuan, Y., Gretzel, U., \& Tseng, Y.-H. (2015). Revealing the nature of contemporary tourism research: Extracting common subject areas through bibliographic coupling.

International Journal of Tourism Research, 17, 417-431.

Zehrer, A. (2007). The justification of journal rankings - A pilot study. Scandinavian Journal of Hospitality and Tourism, 7, 139-156.

Zhao, W., \& Ritchie, J. B. (2007). An investigation of academic leadership in tourism research: 19852004. Tourism Management, 28, 476-490. 